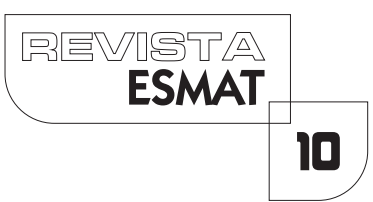

\title{
DIREITO PENAL E A DEFESA DA PROPRIEDADE NO BRASIL: REFLEXOS NA QUESTÃO AGRÁRIA
}

CRIMINAL LAW AND THE DEFENSE OF PROPERTY IN BRAZIL: REFLECTIONS ON LAND ISSUES

Nayana Guimarães Souza de Oliveira

Mestranda em Direito Agrário pela Universidade Federal de Goiás (conclusão prevista para 20 I6); bacharel em Direito pela Universidade Federal de Ouro Preto (20 I4); assessora técnica do Tribunal de Justiça do Tocantins-TO.E-mail: nayana_guimaraes@yahoo.com.br

\section{RESUMO}

Objeto de estudo é a relação entre estrutura social, disciplina da força de trabalho e encarceramento no Brasil, adotando como pressupostos as conclusões das pesquisas de Georg Rusche e Otto Kirchheimer, Dario Melossi e Mássimo Pavarini, segundo os quais (I) o cárcere é instituição auxiliar da fábrica porque mantém níveis salariais adequados para a valorização do capital e (II) a criminalidade é dependente do grau de desenvolvimento econômico de dada sociedade (estrutura social). Busca-se comprovar que o sistema penal que vigorou e vigora no Brasil promovem a defesa da propriedade enquanto instituição excludente e mantenedora das desigualdades sociais, mormente como o cárcere se aliou à fábrica, de modo a assegurar a continuidade de um sistema fundiário desigual, e de que maneira o Estado reproduziu essa estrutura por meio da legislação e de seus órgãos institucionais.

PALAVRAS-CHAVE: Direito agrário; Direito penal; História da pena.

\section{RESUMEN}

El objeto de estudio es la relación entre la estructura social, la disciplina del trabajo y el encarcelamiento en Brasil, teniendo por sentado las conclusiones de las investigaciones de Georg Rusche y Otto Kirchheimer y Dario Melossi y Massimo Pavarini, según las cuáles (i) la prisión es la institución de ayuda de la fábrica porque mantiene los niveles salariales adecuados, para la acumulación de plusvalías y (II) el delito depende del grado de desarrollo económico de una dada sociedad (estructura social ). El objetivo es 
demostrar que el sistema de justicia penal en vigor en Brasil promove la defensa de la propiedad como institución exclusiva y patrocinador de las desigualdades sociales, sobre todo porque la prisión se ha asociado a la fábrica con el fin de garantizar la continuidad del sistema de tenencia de la tierra desigual, y cómo el Estado ha reproducido esta estructura a través de la legislación y de sus órganos institucionales.

PALABRAS CLAVE: Derecho agrario; Derecho penal; Historia de la pena.

\section{APRESENTAÇÃO}

desenvolvimento brasileiro, ao longo do processo de implementação e consolidação do capitalismo na economia, deu-se com o contorno dos obstáculos existentes diante do processo de acumulação do capital, sem o necessário enfrentamento de diversas questões sociais a ele relacionados, como a questão do acesso à terra (BUAINAIN, 1997, p. 17).

Essa ausência de enfrentamentos é a explicação para a permanência da concentração fundiária, que, por sua vez, é uma das causas da criminalidade no campo. A reprodução do padrão de acumulação fundiária perpetuou a questão agrária, que se traduz em conflitos.

Segundo dados da Comissão Pastoral da Terra' (CPT, 20I5), em 2014 foram registradas mil e dezoito ocorrências, doze mil, cento e dezoito despejos, trinta e seis assassinatos, e 56 cinquenta e seis tentativas de assassinato relacionadas à luta pelo acesso à terra. $\mathrm{Na}$ Carta do Encontro do Cerrado, ocorrido de $2 \mathrm{I}$ a 23 de setembro de 2014, em Brazabantes, Goiás, Brasil, a CPT e outras entidades sociais articuladas defenderam, como um dos itens da pauta, que a luta pela Reforma Agrária não seja criminalizada; que, ao contrário, o Poder Público opte pela democratização da terra (CPT, 20|4).

Extraem-se dados da historiografia do sistema legal de proteção à propriedade privada no Brasil (que ora se denomina "defesa da propriedade), para verificar como o cárcere serve de instrumento para a perpetuação do direito a terra como prerrogativa de poucos. Trata-se de estudar como, no Brasil, o cárcere se aliou à fábrica (MELOSSI; PAVARINI, 2006) para assegurar a continuidade de um sistema fundiário desigual.

'Comissão Pastoral da Terra é um órgão da Conferência Nacional dos Bispos do Brasil (CNBB), criada em Goiânia, Goiás, Brasil, em julho de 1975, conforme informações obtidas no Centro de Documentação e Informação Científica Prof. Casemiro dos Reis Filhos, no sítio eletrônico da PUC-SP, endereço virtual http://www.pucsp.br/cedic/colecoes/pastoral_da_terra.html. Acesso em 3 de janeiro de 2016. 
Na primeira parte, colocam-se os pressupostos fundamentais da pesquisa, demonstrando a relação existente entre o grau de desenvolvimento econômico da sociedade (estrutura social) e os métodos de punição sustentáculos dessa estrutura; a segunda demonstra como a relação da estrutura social/métodos de punição significou a defesa do direito de propriedade no Brasil.

O raciocínio hipotético-dedutivo pautou a realização da pesquisa, porque existem expectativas ou conhecimentos prévios expostos na primeira parte do texto a serem confirmados ou refutados na investigação promovida na segunda parte do artigo (GUSTIN; DIAS, 20।3, p. 23).

\section{CÁRCERE E FÁBRICA, UMA EXPLICAÇÃO NECESSÁRIA}

Rusche e Kirchheimer (2004) lograram demonstrar, com propriedade, a interrelação entre punição e estrutura social, retratando como a pena se manifesta de formas específicas de acordo com o grau de desenvolvimento econômico de cada sociedade.

Os autores consideraram, em sua obra, que a pena possui fatores condicionantes negativos e fatores condicionantes positivos.

O fator condicionante negativo se dá pela crença social de que determinada pena é capaz de dissuadir as pessoas de cometerem crimes. Para tanto, o criminoso deve viver de maneira pior que o mais desfavorecido dos cidadãos de bem. Já o fator condicionante positivo seria o estágio de desenvolvimento econômico: a escravidão só seria possível numa economia escravista, da mesma forma que o trabalho forçado somente existiria numa economia manufatureira ou industrial, e as fianças e numa economia monetária (RUSCHE, KIRCHHEIMER, 2004, p. 20).

O cenário avaliado pelos autores é o europeu do século XV até a ascensão do nazismo, no pós I Guerra Mundial.

Demonstram que, na Baixa Idade Média, os métodos punitivos mais adotados eram os da indenização e da fiança, fato que os autores explicam com base na existência de terra suficiente para atender ao crescimento constante da população sem baixar o nível de vida.

Entre o século XIV e o XV, ocorre a transição para o capitalismo, amparada pela criação de leis criminais mais severas. A fiança não seria capaz de atingir o intento repressivo e dissuasivo que justificava a sua existência, assim, o castigo físico, o exílio e a pena de morte se tornaram as formas regulares de punição.

Se, em séculos passados, a forma de punição mais adotada era patrimonial, pois existiam terras suficientes para o sustento da estrutura social, na passagem para o capitalismo é necessário implementar novas e mais duras punições.

No final do século XVI, na Inglaterra mercantilista, o desenvolvimento econômico levou à adoção do trabalho de prisioneiros como forma de punição. Some-se a isso o baixo crescimento demográfico, em razão das guerras religiosas e distúrbios internos. Foi necessária, assim, a atuação do Estado no sentido de tabelar salários, impedir a 
emigração de trabalhadores, estimular a natalidade e combater a mendicância.

Nesse contexto, as casas de correção em Londres e as galés aproveitavam a mão de obra dos "indesejáveis", treinando-os para o trabalho na indústria. Nas galés, os presos eram compelidos a fazer trabalhos penosos e arriscados, que os homens livres não fariam.

Com a melhoria das condições de vida dos trabalhadores no final do século XIX até 19|4, o encarceramento passou a ser visto como "atraso", e a teoria acompanhou o movimento econômico no sentido de recomendar a prevenção criminal. Assume-se a ideia de que a política social é a forma adequada para combater o crime, e a punição deve exercer função educativa.

Nada mais conveniente! A erupção da I Guerra Mundial levou à utilização de prisioneiros para colaboração na empresa dos países em guerra, como, por exemplo, para a confecção de material bélico na Inglaterra.

A política criminal exsurgiu de todo o histórico levantado por Rusche e Kirchheimer, como uma válvula para regular o fluxo da criminalidade. Para os autores, "a criminalidade não é afetada pela política penal, mas está intimamente dependente do desenvolvimento econômico" (RUSCHE; KIRCHHEIMER, 2004. p. 273).

O trabalho de Rusche e Kirchheimer foi continuado na obra "Cárcere e Fábrica", de Dario Melossi e Massimo Pavarini (20।4). Demonstra-se que o cárcere é instituição auxiliar da fábrica porque é utilizado para manter os salários em patamares adequados para a valorização do capital.

Adota-se, pois, como pressuposto da presente pesquisa, que (I) a criminalidade é dependente do desenvolvimento econômico e (II) o cárcere é instituição auxiliar da fábrica, que, num sistema capitalista, tem um objetivo primordial: a lucratividade.

\section{HISTORIOGRAFIA DO DESENVOLVIMENTO CAPITALISTA NO BRASIL: A DEFESADA PROPRIEDADE}

A primeira providência de Portugal, ao "achar" o Brasil, foi conceder três cartas régias a Martim Afonso de Souza: uma delas para que tomasse posse das terras em nome do Rei; a segunda para nomeá-lo capitão-mor e governador das terras descobertas; e a última para torná-lo sesmeiro do Rei, entregando sesmarias a quem desejasse.

Em Portugal, as sesmarias estavam ligadas ao movimento de fixação populacional nos territórios reavidos após a Guerra de Reconquista, à estabilização militar e à necessidade de tornar a terra próspera, economicamente (RAU, 1982, p. 28-29).

No Brasil, por outro lado, objetivavam a ocupação das terras que Portugal considerou vagas. Em terrae brasilis as sesmarias não ameaçavam o caráter absoluto da propriedade.

Lígia Osório Silva (2008) afirma que, até o século XVII, as doações eram gratuitas e condicionadas ao aproveitamento do solo, com prazo estipulado na carta de doação. Contudo, a ausência de meios de controle pelas autoridades portuguesas dificultava 
sobremodo o cumprimento das referidas normas.

A partir do século XVII, criaram-se normas para estruturar a propriedade do solo, para que a terra cumprisse o objetivo de acumular capital para a metrópole. Assim, as concessões de sesmarias para candidatos abastados, com a finalidade de estabelecer engenhos de açúcar, eram atendidas rapidamente.

Em meados do século XVII e início do século XVIII, exigiu-se o pagamento de foro pelas sesmarias, aumentando-se o controle sobre as concessões. Em 1697, limitou-se à extensão das concessões; na sequência, em 1698, exigiu-se a confirmação pelo El-Rei das sesmarias concedidas.

O acesso à terra, dificultado aos próprios portugueses, é praticamente impossibilitado para os nativos, para os quais resta a escravidão ou a fuga para o interior do país.

Por volta de I53 I, iniciou-se o tráfico negreiro para a Colônia, ante a dificuldade de escravizar os índios nativos. Girolamo Domenico Treccani demonstrou que a substituição destes se deu por uma razão econômica, a vantagem do tráfico triangular: na África, os mercadores trocavam mercadorias europeias por cativos; e nas Américas, os nativos eram a moeda de troca para obtenção de mercadorias tropicais, vendidas na Europa.

Assim, a estrutura social montada no Brasil da época serviu aos interesses econômicos da Metrópole; da mesma forma, o direito penal.

A resistência negra, à época, enfrentou verdadeiras milícias paraestatais formadas por capitães do mato, uma profissão regulamentada pelo Regimento (TRECCANI, p. 45). O poder punitivo-repressor estava nas mãos de particulares, referendado pelo Estado.

É relevante notar que, embora os escravos fossem tratados como se coisas fossem, para o Código Penal da época eram verdadeiros seres humanos: a lei penal expressamente permitia a punição da fuga para os mocambos (TRECCANI, p. 59). O Código Penal do Império, de 16 de dezembro de 1830, com efeito, tipificava o crime de "insurreição". Quando vinte ou mais escravos se houvessem libertado por meio da força, cominando-lhes, no grau máximo, pena de morte, no grau médio, galés perpétuas, e quinze anos de açoutes, no mínimo.

Legitimou-se uma prática econômica lucrativa pela legislação penal, criminalizando a resistência negra; ao mesmo tempo, impossibilitou-se o acesso à terra por índios e negros. Assim também nos períodos que se seguem.

A Proclamação da Independência, em 1822, veio desacompanhada de qualquer tipo de luta por mudanças no regime de propriedade, na política escravista e quilombola, a despeito de importantes movimentos populares de resistência, a exemplo da cabanagem e da sabinada.

Domenico Treccani (p. 76) mencionou que o projeto de Constituição, datado de 1823, previa, no artigo 254, sobre a catequese e civilização dos indígenas, a emancipação lenta dos negros e a sua educação religiosa e industrial. Este artigo não 
integrou o texto final da Constituição, de I 824, outorgada pelo Imperador Dom Pedro I.

Pressionado pela Inglaterra, em 1827, Dom Pedro I ratificou um decreto imperial para determinar o fim do Tráfico Negreiro. Em 1830, o Código Penal Imperial tipificou o delito de escravizar pessoa livre; em I831, a Lei, de 7 de novembro, determinou a libertação de todos os escravos que ingressassem no Brasil a partir de então. Contudo, o tráfico aumentou nas décadas seguintes, e somente se pôs fim a ele, definitivamente, quando interesses econômicos da Inglaterra foram afetados, com o fim da escravidão nas Antilhas.

Na conjuntura Metrópole/Colônia e mesmo após a Independência, quando a existência de uma "realeza portuguesa" no Brasil impedia que o país buscasse os seus próprios interesses, a escravidão era um sistema lucrativo a ser mantido, em virtude do comércio triangular já mencionado. Os métodos punitivos legitimados pelo Direito estatal, por sua vez, atuavam como verdadeiros meios disciplinantes para o trabalho. A fábrica aliou-se ao cárcere, servindo a prisão como meio para criminalizar e dissuadir qualquer movimento com vista à modificação do status quo; isso até que a então potência inglesa exigisse a abolição da escravidão, supostamente em favor dos novos ventos liberais.

Em 1822, Dom Pedro I suspendera as sesmarias por meio da Resolução n 76 . Até 1850, vigorou no Brasil o que se denominou "período áureo das posses". É dizer que, neste meio tempo, a aquisição de terras no Brasil não estava regulamentada, não dependia de concessão do Rei nem de outro documento ou título.

A Lei de Terras, de I 850, foi aprovada após amplo debate que envolveu a libertação dos escravos e a doação de fazendas aos ex-escravos. A proposta não vingou, e a Lei de Terras em seu artigo ${ }^{\circ}$ proibiu a aquisição de terras devolutas por outro título que não o da compra, criminalizando, no artigo $2^{\circ}$, a conduta de se apossar de terras devolutas ou alheias, derribar matos ou colocar fogo, com pena de dois a seis meses de prisão, multa e satisfação do dano.

É sobremodo relevante o porquê de uma Lei voltada para a regulamentação de terras prever, em seu bojo, tipos penais e respectivos preceitos secundários. A prisão reaparece, pois, como mantenedora de uma estrutura social escravista, de modo a beneficiar as classes privilegiadas da população brasileira. Treccani (p. 93) enxerga, na vedação do acesso à terra aos escravos libertos e na legalização de sua incorporação pelos latifundiários, o tratamento da questão fundiária como uma questão policial.

A lei de terras, ademais, se pôs a criar o trabalho assalariado. $\bigcirc$ Estado golpeou o capital traficante, consolidou a legislação comercial, regularizou o direito de propriedade e implantou o trabalho livre, por meio da importação de imigrantes.

Destarte, a Lei n 60 I , de 1850, representou a confluência dos interesses do Estado Brasileiro nascente e dos grandes proprietários de terras: o objetivo do Estado era formar uma mão de obra assalariada, e o dos grandes proprietários traduzia-se na necessidade de substituir a mão de obra escrava. Tudo isso, não se deve perder de vista, 
sem possibilitar aos recém-libertos e aos índios o acesso à terra - cuja única forma de acesso era a compra -; e, por outro lado, punindo-os caso invadissem terras, ainda que vagas e pertencentes ao Estado. Vejamos a continuidade desse modelo nos períodos posteriores.

A Proclamação da República, em 15 de novembro de 1889, encabeçada pelo marechal Deodoro da Fonseca, representou a chegada da modernidade no Brasil, as primeiras políticas de industrialização, a modificação da política relativa ao voto popular.

Smith (1990) analisou a formação da propriedade fundiária enquanto propriedade mercantil da terra: a partir da década de 1840, surgiu um sentimento anticolonial, dada a possibilidade de guerras e instabilidade, fatores contrários aos interesses do capital.

Bentham e James Mill começaram, pois, a levantar ideários de emancipação das colônias, de acordo com a visão da "missão civilizadora do capitalismo", de impor uma ordem universal burguesa. Por sua vez, Torrens e Wakefield se contrapuseram ao sentimento colonial vigente na época e fundaram a Colonization Society, com o objetivo de substituir a prática de imigração pela colonização sistemática, de modo a trazer benefícios para a pátria colonizadora, vertente conhecida por "neocolonialismo".

○ Brasil aderiu à vertente neocolonizadora. Aplicando Wakefield, a República passou a incentivar o recebimento de imigrantes, suspender as doações de terras e criar um mercado de terras. Fez-se a escolha entre dois modelos: a linha farmer (estadunidense) e a linha prussiana. A primeira significava a escolha de um modelo de agricultura; por sua vez, a via prussiana representava a agricultura de exportação, dominada por grandes fazendeiros (LINHARES; TEIXEIRA, 1999, p. 7I). Prevaleceu, nos debates travados à época, a linha prussiana, e os projetos relacionados à abolição foram abandonados, assim como os de modernização da propriedade fundiária.

Segundo Francisco de Oliveira (1989), foi nesse cenário que a burguesia agrária se transmudou em oligarquia. Maria Yedda Linhares e Francisco Carlos Teixeira Silva ( 1999, p. 69) escreveram que houve uma conjunção do ideário liberal com o conservadorismo, num pacto de governança oligárquica conservadora, que fortaleceu os poderes locais.

A República Velha sustentou-se, até 1930, com a violência estatal (LINHARES; TEIXEIRA, 1999, p. 79), a reprimir qualquer tentativa de questionamento da ordem social vigente, como Canudos, Contestado, e o cangaço. Enquanto na Europa das primeiras décadas do século $X X$ as escolas positivas ensinavam a defesa social preventiva ou repressiva ao criminoso, em vez do castigo (pena), como método para combate da criminalidade, no Brasil prevalecia a reprimenda sem a adoção de qualquer tipo de política social. Apesar de não existir uma burguesia capitalista no Brasil, a ordem agrário-conservadora da República Velha impunha o elogio do mundo do trabalho aliado a sistemas repressivos eficientes (LINHARES; TEIXEIRA, 1999, p. 8I).

O Código Penal da República, de 1890, previa como penas, em seu artigo 43, a prisão celular, o banimento, a reclusão, a prisão com trabalho obrigatório, a prisão disciplinar, a interdição, a suspensão e perda do emprego público, e a multa. No artigo 
45, dispunha que a pena de prisão celular deveria ser cumprida em estabelecimento especial com isolamento celular e trabalho obrigatório. Tais disposições vêm a confirmar a ideologia conservadora-agrarista nos moldes expostos por Linhares e Teixeira ( 1999), a saber, a pena aproximada do elogio ao trabalho, ambos meios de controle social.

De acordo com Vera Malagutti Batista (20 I I), as leis penais brasileiras foram "modernizações" das Ordenações Filipinas. É dizer, essas Ordenações foram paulatinamente "melhoradas" pelo Código Criminal do Império ( 1830$)$; pelo Código Penal da República (1890); pela Consolidação das Leis Penais (1932); e pelo Código Penal, de 1940 (modificado pela Lei n 7.209, de 1984).

No entanto, com a Revolução, de 1930, após a falência do sistema de alternância de poder, criam-se, pela primeira vez, condições para uma modificação efetiva do ordenamento agrário no Brasil, uma vez que o setor agrícola passava por uma crise, diante do crash, de 1929. No entanto, Vargas deixou de promover a necessária reforma agrária.

Vargas rompeu com a política da antiga República, agro-exportadora, priorizando a produção para o mercado interno. Ampliou o espaço da fábrica, nos moldes fordistas, criando "o bom trabalhador", no ambiente das recém-instaladas estatais. Estabeleceu uma política salarial única, incentivou a mobilidade da fronteira econômica, a ocupação dos espaços vazios. Exigiu, a partir de 1933, a regularização das propriedades e implementou a desapropriação; centralizou as terras devolutas nas mãos da União... Enfrentou, pois, com diversas medidas, os poderes oligárquicos estabelecidos nos estados.

○ campo passou a participar do desenvolvimento nacional, mas não houve enfrentamento direto dos poderes das oligarquias: não se realizou a reforma agrária nem se estendeu aos trabalhadores rurais os direitos concedidos aos urbanos. Propositalmente, Vargas propôs a ocupação das fronteiras no oeste, mas evitou conflitos com os latifúndios estabelecidos em áreas consolidadas, como no nordeste brasileiro.

No imaginário brasileiro, Linhares e Pinheiro (1999) escrevem que vigorou o elogio do trabalho: a malandragem, a boemia, a mendicância eram reprimidas pela polícia. Havia um projeto social de ordenamento para o trabalho de massa. O campo e a cidade tiveram seus papéis definidos pela política estatal varguista.

De fato, foi na Era Vargas que se apresentou uma questão agrária no Brasil, pois foi em seu governo que o campo ganhou um lugar no desenvolvimento nacional. Até então, diante da ausência da indústria, o campo era a única possibilidade, a única "vocação" do país.

A Marcha para o Oeste iniciou um processo de expansão da fronteira no Brasil, a partir de 1943. É dizer, os fazendeiros expandiram suas fazendas, "empurrando" trabalhadores e camponeses livres, indígenas e remanescentes de quilombos, para as regiões de fronteiras.

A ideologia da Marcha para o Oeste, contudo, não iluminou as contradições da ambivalência representada pela política rural assumida por Getúlio; pelo contrário, 
disseminou-se uma ideologia do homem brasileiro enquanto fusão de raças, enquanto união, "inexistência de diferenças".

Essa concepção manifestou-se nos mecanismos repressivos e penais da Era Vargas, pelo controle social exercido pelo Departamento de Ordem Política e Social (DOPS), e pelo Departamento de Imprensa e Propaganda (DIP). Encarceraram-se sujeitos contrários ao sistema vigente, muitas vezes sob a justificativa de ameaça comunista.

Algumas figuras ilustres foram presas durante esse período, a exemplo de Graciliano Ramos e Apolônio de Carvalho, este militante na Aliança Nacional Libertadora. A estimativa, segundo Marcelo Badaró Mattos (20 I I), é de que cerca de trinta e cinco mil pessoas teriam sido presas por motivação política, naquela conjuntura.

Com a Revolução, de 1930, Vargas deu ao desembargador Vicente Piragibe o encargo de consolidar as leis extravagantes que modificavam o conteúdo do Código Penal então vigente, datado de 1890. Por meio do Decreto n²2.213, de 1932, aprovou-se a Consolidação das Leis Penais de Piragibe, a qual passou a ser precariamente o Estatuto Penal Brasileiro, sem grandes alterações em seu conteúdo.

Iniciado o período do Estado Novo, em 1937, passou a viger o Código Penal de 1940 (Decreto-Lei n².848), ainda hoje em vigor. O Codex é uma homenagem ao direito de propriedade no Brasil, senão vejamos.

A pena para o crime de homicídio é de seis a vinte anos; para o homicídio qualificado, é de até trinta anos. Isso leva à conclusão de que o homicídio qualificado é aquele cuja pena cominada é a maior no Código Penal? Certamente, não. Para a lei, o latrocínio seria mais grave: a pena mínima para este crime, classificado em crime contra o patrimônio, é de doze anos, maior que a pena mínima prevista para o homicídio. Para a extorsão mediante sequestro que dura mais de vinte e quatro horas, caso o sequestrado seja menor de dezoito anos ou maior de sessenta anos, a pena mínima é de oito anos; se resultar lesão corporal ou morte, a pena é de doze anos, ambas maiores que a prevista para o homicídio.

A disparidade existente na legislação penal é um retrato da realidade social, que, com relação ao direito de propriedade, permanece ao longo da história.

Após breve retorno de Vargas (1950-1954) e a assunção da presidência por um governo interino, assumiu, por meio de eleições, Juscelino Kubistchek. Segundo Vânia Maria Losada Moreira (2003, p. 157), os principais desafios assumidos pelo novo governo, cujo slogan se traduziu na campanha "50 anos em 5", foram: acelerar o desenvolvimento econômico, implantando novas indústrias; construir a capital do Brasil; e integrar os estados brasileiros por meio da construção de capitais e estradas.

Juscelino continuou o modelo de industrialização em curso no Brasil desde o Estado Novo (MOREIRA, 2003, p. I6I), baseado na presença do capital estrangeiro. Diferenciou-se, no entanto, por enfatizar a substituição de importações, enquanto Getúlio Vargas havia focado a produção de bens de capital.

De acordo com Moreira (2003), Kubistchek evitou tomar partido em qualquer política agrária, ignorando a ampliação dos conflitos agrários e o crescimento dos 
movimentos sociais, como as Ligas Camponesas e a politização no campo. Ademais, Juscelino teria contribuído para a expansão do modelo oligárquico, pois não se preocupou em disciplinar as ocupações, em que pese continuar apoiando o ímpeto colonizador da "Marcha para o Oeste".

Nos "anos JK", os interesses da oligarquia rural aderiram ao plano nacionaldesenvolvimentista encabeçado pelo presidente da República. A partir da década de 1950, a reforma agrária passou a ser um discurso corrente em todos os grupos políticos, prevalecendo a sua concepção como "modernização do campo", e não como reforma agrária no sentido de garantia do acesso à terra aos que não a têm.

A opção política de Juscelino, no entanto, significou a maior apropriação do solo nacional, em prejuízo das populações pré-existentes no Norte e Centro-oeste, excluídos da nova "Marcha para o Oeste", conforme esclareceu Moreira (2003).

De outro modo, assistiu-se à conformação do capital industrial e da oligarquia, a significar o arraigamento do sistema capitalista de produção, em moldes democráticos. Para Moacir Palmeira (1989), ocorreu, entre os anos 1950 e 1960, um processo de modernização conservadora, que ele descreveu como concentração da propriedade, disparidade de renda, êxodo rural, aumento da taxa de exploração da força de trabalho nas atividades agrícolas, aumento da taxa de autoexploração nas propriedades menores, piora da qualidade de vida no campo. É nesse cenário que o governo militar assumiu, após breve passagem de Jânio Quadros e João Goulart.

A resposta às insatisfações manifestas na década de 1950 veio, conforme BUAINAIN (2008), na forma do Estatuto do Trabalhador Rural ( 1963 ) e do Estatuto da Terra (1 964). Para este autor, "(...) o Golpe Militar de 1964 foi, pelo menos em parte, motivado pela intensificação do conflito agrário, que era então percebido como de grande potencial "revolucionário" (p. 28). A grande solução apontada pelo Estatuto da Terra seria a tomada de duas medidas: colonização e exigência do cumprimento da função social da propriedade.

Ruy Moreira (1986) elencou os três parâmetros mais gerais do Estatuto da Terra, a vinculação do uso da terra ao aumento da produtividade, a definição da empresa rural como objetivo, e a industrialização do campo.

Para Wenceslau Gonçalves Neto ( 1997), o Estado garantiu a mediação das classes, de modo a privilegiar a burguesia, disciplinar a classe trabalhadora e garantir a sua reprodução social, perpetuando as formas de acumulação dominantes na sociedade.

De 1964 a 1966, o ministro Roberto de Oliveira Campos lançou o Programa de Ação Econômica do Governo (PAEG), que propôs a Reforma Agrária, significando: educação, novos esquemas de tributação da terra, organização cooperativa, melhoria do crédito rural e colonização de "espaços vazios". Percebe-se claramente a continuidade do modelo anterior.

Já de 1968 a 1970, o ministro Hélio Beltrão, durante o governo Costa e Silva, colocou em pauta as Diretrizes do Governo e o Programa Estratégico de Desenvolvimento (Plano Trienal) para aumentar a produtividade agrícola e romper as 
barreiras do abastecimento.

Seguiu-se o governo de Médici ( 970 a 1973), período conhecido como "milagre brasileiro" quando se lançou o I Plano Nacional de Desenvolvimento (PND). Aboliu-se a referência à reforma agrária do texto, utilizando-se termos mais amenos, como "racionalização da agricultura" e "redistribuição de terras".

O II PND nasceu num contexto não tão favorável, em plena crise do petróleo e esgotamento do "milagre", durante o governo Geisel. Seus objetivos foram mais modestos, conter a inflação, retomar o crescimento, manter em equilíbrio a balança de pagamentos, promover a melhoria de renda, preservar a ordem social e política.

Dessa forma, embora o Estatuto da Terra tivesse aberto possibilidades para a adoção de diferentes vias de desenvolvimento agrícola, em sua ambiguidade, o Estado acedeu à via da modernização do latifúndio, em vez da priorização da formação da agricultura familiar. Vale notar, outrossim, que Estatuto da Terra não se refere ao camponês expropriado no transcorrer da década de 1950: para o camponês tradicional não há política pública possível.

O Código Penal vigente, datado de 1940, regulamentava o poder repressivo estatal no período, contudo, há uma atuação desmedida do Estado para a manutenção do status quo, ademais na questão agrária e dos conflitos no campo.

Com a redemocratização, acirrou-se a conflituosidade no campo. Os setores agrários desfavorecidos esperavam obter ganhos com a democratização; por outro lado, a resistência dos proprietários ofereceu uma resposta violenta, que a Comissão Pastoral da Terra monitorou por meio de documentação exposta em seu sítio eletrônico, a partir de 1985.

Em 1986, foi lançado o I Plano Nacional da Reforma Agrária (PNRA), com uma proposta para conciliar o marco jurídico definido pelo Estatuto da Terra com uma ação massiva de desapropriações das terras consideradas improdutivas. Porém, o documento oficial do I PNRA resultou bem mais brando, impondo a impossibilidade de desapropriar latifúndios cumpridores da sua função social e áreas com alta incidência de parceiros e meeiros.

Conforme Ruy Moreira ( 1986 ), quando o governo da Nova República anunciou a "Proposta para Elaboração do I PNRA", proprietários de terras e mídia se mobilizaram, e aumentou o número de assassinatos a camponeses e lideranças sindicais. A Sociedade Rural Brasileira (SRB) e a Confederação Nacional da Agricultura (CNA) seguiram para Brasília para reivindicar mudanças no conteúdo do Plano.

Para Buainain (1997), "o resultado da luta política nesse período é que a mobilização dos proprietários na Constituinte de 1988 limitou o próprio Estatuto da Terra, restringindo as possibilidades de responder à crise e aos conflitos com ações de reforma agrária" (p. 36). Demonstrou o autor, por meio do estudo de dados da CPT e da Ouvidoria, que, entre 1997 e 1999 - salvo ligeira queda em 2000 -, o aumento da pressão social em torno da reforma agrária cresceu, o que se verificou pelo aumento do número de prisões no período em questão. 
A estrutura social vigente - entendida como um continuum de uma política que desviou os olhos de seus problemas sociais -, é a ponte encontrada para a inter-relação entre a defesa da propriedade no sistema político-jurídico brasileiro e o sistema punitivo vigente.

\section{CONSIDERAÇÕES FINAIS}

Leonilde Servolo estudou, em sua publicação no Caderno de Conflitos no Campo, publicado pela Comissão Pastoral da Terra (CPT), em 20।4, os conflitos agrícolas no Brasil em três escalas temporais: nos últimos trinta anos, nos últimos dez anos, e em 2014. Os dados coletados demonstraram, para a autora, a continuidade dos conflitos pela terra em patamares semelhantes aos dos anos anteriores; da mesma forma, permaneceram altos o número de assassinatos e tentativas de assassinatos, de pistolagem e outras formas de violência.

Neste artigo, o que se propôs e se tentou observar foi a relação entre os elementos estrutura social - defesa da propriedade - e encarceramento, a fim de comprovar como o direito penal arregimenta e penaliza indivíduos de modo a servir ao sistema econômico vigente.

Esta análise partiu de alguns pressupostos, extraídos das obras de Rusche e Kirchheimer (2004) e Melossi e Pavarini (20|4). São eles: (i) o cárcere é e foi responsável pela disciplina da força de trabalho, ou seja, o cárcere é instituição auxiliar da fábrica porque mantém níveis salariais adequados para a valorização do capital; (ii) a criminalidade é dependente do grau de desenvolvimento econômico de dada sociedade (estrutura social).

Logrou-se observar que, no Brasil, vem-se perpetuando um sistema jurídico excludente, limitador do acesso à terra, enquanto se defende a formação do brasileiro "bom trabalhador". A reprimenda ao sindicalismo e aos movimentos sociais veio e vem também nesse contexto, pois o sistema penal atua para garantir a continuidade dessa estrutura, confirmando-se a hipótese proposta.

\section{REFERÊNCIAS}

ABRAMOVAY, Ricardo. Paradigmas do capitalismo agrário em questão. São Paulo: Editora Hucitec; Campinas: Editora Unicamp, 1998.

BARBOSA, Licínio Leal. Traços Gerais da Reforma Penal. In: Revista da Faculdade de Direito UFG, v. 6, n. I , p. 23-32, 1982.

BATISTA, Vera Malaguti. Introdução Crítica à Criminologia Brasileira. Rio de Janeiro: 
Revan, 20II.

BUAINAIN, Antônio Márcio (org). Luta pela terra, reforma agrária e gestão de conflitos no Brasil. Campinas: Editora UNICAMP, 2008.

Código Penal Brasileiro, de 16 de dezembro de 1830. Disponível em http://www.planalto.gov.br/ccivil_03/leis/LIM/LIM-16-12-1830.htm

Decreto $\mathrm{n}^{\circ} 847$, de II de outubro de 1890. Disponível em http://www2.camara.leg.br/legin/fed/decret/I 824- I 899/decreto-847- I I-outubro| 890-503086-norma-pe.html

DELGADO, Guilherme Costa. Do capital financeiro na agricultura à economia do agronegócio: mudanças cíclicas em meio século ( 1965-20 I2). Porto Alegre: Editora da UFRGS, 2012.

DOTTI, René Ariel. A urgente Consolidação das Leis Penais. Disponível em: <http://www.uniaraxa.edu.br/ojs/Index.php/juridica/article/viewFile/I08/99>.

GONÇALVES NETO, Wenceslau. Estado e agricultura no Brasil: política agrícola e modernização econômica brasileira - 1960-1980. São Paulo: Editora Hucitec, 1997.

GUSTIN, Miracy Barbosa de Sousa; DIAS, Maria Tereza da Fonseca. (Re)pensando a pesquisa jurídica: teoria e prática. 4. ed. Belo Horizonte: Del Rey, 2013.

JULIÃO, Francisco. Que são as ligas camponesas?, 1962. In: WELCH, Clifford A. (et al) Camponeses brasileiros: leituras e interpretações clássicas. São Paulo: Editora UNESP; Brasília: Núcleos de Estudos Agrários e Desenvolvimento Rural, 2009. Lei n 60 I, de I8 de setembro de 1850 . Disponível e m : <http://www.planalto.gov.br/civil_03/LEIS/L060 I- | 850.htm>.

LINHARES, Maria Yedda \& SILVA, Francisco Carlos Teixeira. Terra prometida: uma história da questão agrária no Brasil. Rio de Janeiro: Campus, 1999.

MARÉS, Carlos Frederico. A função social da Terra. Curitiba: Sérgio Antônio Fabris Editor, 2002.

MARTINS, José de Souza. Fronteira: a degradação do outro nos confins do humano. São Paulo: Editora Hucitec, 1997. 
MARX, Karl. A origem do capital: a acumulação primitiva. 5. ed. São Paulo: Global Editora, 1985.

MATOS, Elaine Saraiva; CUNHA, Gabriela Bento; ALENCAR, Francisco Amaro Gomes de. Panorama dos conflitos e da violência no espaço agrário brasileiro de 1985 20 I. In: Conflitos no Campo-Brasil 20 I4. Brasil: CPT Nacional, 20 I4.

MATTOS, Marcelo Badaró. Memórias da prisão política sob o regime de Vargas. In: Anais do XXVI Simpósio Nacional de História - ANPUH. São Paulo: 201 I . Disponível em: <http:www.snh20 I I.anpuh.org/resources/anais/I4/I299634656_ARQUIV O_a npuh20 I I.pdf $>$.

MATTOS, Virgílio. Trem de doido: o direito penal e a psiquiatria de mãos dadas. Belo Horizonte: Una Editora, 1999.

MEDEIROS, Leonilde Servolo. Conflitos fundiários e violência no campo. In: Conflitos no Campo-Brasil 20 I4. Brasil: CPT Nacional, 2014.

MONTENEGRO, Antônio Torres. Ligas Camponesas e sindicatos rurais em tempo de revolução. In: FERREIRA, Jorge \& DELGADO, Lucília de Almeida Neves (orgs.) O Brasil Republicano: $\bigcirc$ tempo da experiência democrática - da democratização de 1945 ao golpe civil-militar de 1964. Rio de Janeiro: Civilização Brasileira, 2003.

MORAES, Clodomir Santos de. História das Ligas Camponesas do Brasil, 1969. In: STÉDILE, João Pedro (org). História e Natureza das Ligas Camponesas - I 954- 1964. São Paulo: Expressão Popular, 2006.

MOREIRA, Ruy. O Plano Nacional de Reforma Agrária em Questão. In: Revista Terra Livre, nº 0 I, ano I. São Paulo: Associação dos Geógrafos Brasileiros, 1986.

MOREIRA, Vânia Maria Losada. Os anos JK: industrialização e modelo oligárquico de desenvolvimento. In: FERREIRA, Jorge \& DELGADO, Lućlia de Almeida Neves (orgs). O Brasil Repúblicano: $\bigcirc$ tempo da experiência democrática - da democratização de 1945 ao golpe civil-militar de 1964. Rio de Janeiro: Civilização Brasileira, 2003.

MULLER, Geraldo. Indústria e agricultura no Brasil: do latifúndio-minifúndio ao CAl. \& Formulações gerais sobre o CAl. \& A agricultura Brasileira no CAl. In: MULLER, Geraldo. Complexo agroindustrial e modernização agrária. São Paulo: Editora Hucitec, 1989. 
OLIVEIRA, Francisco de. A economia da dependência imperfeita. 5. ed. Rio de Janeiro: Edições Graal, 1989.

PALMEIRA, Moarcir. Modernização, Estado e Questão Agrária. São Paulo: 1989. Disponível em: http://dx.doi.org/l 0. I590/S0 I03-40| 41989000300006

POLANYI, Karl. A grande transformação: as origens de nossa época. 3. ed. Rio de Janeiro: Campus, 1980.

PORTO-GONÇALVES, Carlos Walter; CUIN, Danilo. O campo se manifesta: a Questão (da Reforma) Agrária. In: Conflitos no Campo - Brasil 2014. Brasil: CPT Nacional, 2014. RAU, Virgínia. As sesmarias medievais portuguesas. Lisboa: Presença, 1982.

SAUER, Sérgio. Processos recentes de criminalização dos movimentos sociais populares. Brasília: 2008. Disponível em: <http://terradedireitos.org.br/wpcontent/uploads/2008/I0/Processos-recentes-de-criminaliza\%C3\%A7\%C3\%A3odos-movimentos-sociais-populares.pdf $>$.

SILVA, Lígia Osório. Terras devolutas e latifúndio. 2. ed. Campinas: Editora Unicamp, 2008.

SMITH, Roberto. A transição no Brasil: a absolutização da propriedade fundiária. In: . Propriedade da terra \& transição: Estudo da formação da propriedade privada da terra e transição do capitalismo no Brasil. São Paulo: Braziliense, 1990.

SMITH, Roberto. Propriedade da terra \& transição: Estudo da formação da propriedade da terra e transição para o capitalismo no Brasil. São Paulo: Brasiliense, 1990.

TRECCANI, Girolamo Domenico. Terras de Quilombos: caminhos e entraves do processo de titulação. Disponível e m $<$ http://www.direito.mppr.mp.br/arquivos/File/Girolamo.pdf $>$.

WANDERLEY, Maria de Nazareth Baudel. Raízes Históricas do Campesinato Brasileiro. In: Anais do XXEncontro Anual da Anpocs. Caxambu: Anpocs, 1996.

Recebido em: 18/01/2016 Aprovado em: 30/09/2016 
